\title{
Comparison of Quality Characteristics of Waxy Wheat Using a Near Isogenic Line
}

\author{
Kanenori Takata*1,3), Zenta Nishio $^{1)}$, Norio Iriki' ${ }^{2)}$, Tadashi Tabiki'), Wakako Funatsuki ${ }^{2}$ ) \\ and Hiroaki Yamauchi') \\ 1) Department of Upland Agriculture Research, National Agricultural Research Center for Hokkaido Region, Shinsei, Memuro, \\ Hokkaido 082-0071, Japan \\ 2) Department of Low-temperature Sciences, National Agricultural Research Center for Hokkaido Region, 1 Hitsujigaoka, Sapporo, \\ Hokkaido 062-0045, Japan \\ 3) Present address: Department of Crop Breeding, National Agricultural Research Center for Western Region, 6-12-1 Nishifukatsu, \\ Fukuyama, Hiroshima 721-8514, Japan
}

Key Words: Triticum aestivum L., hard grain, waxy, quality.

Starch is the principal constituent of wheat endosperm and widely affects properties of food products. A granulebound starch synthase (GBSS), known as waxy proteins, is responsible for amylose synthesis in the endosperm. Three loci $(w x)$ encoding the waxy proteins are located on chromosomes 7AS $(w x-A 1)$, 4AL $(w x-B 1)$ and 7DS $(w x-D 1)$ in hexaploid wheat, respectively. An absence of the three waxy proteins produces waxy wheat (amylose-free). Waxy wheats have been developed through a null allele at $w x-D 1$ or mutations at $w x-D 1$ and crossing with a source of the $w x-A 1$ and $w x-B 1$ alleles (Nakamura et al. 1995, Kiribuchi-Otobe et al. 1997, Yasui et al. 1997). Waxy wheat starch has unique pasting and gelatinization properties in comparison with non-waxy wheat (Yasui et al. 1996, 1999, Kiribuchi-Otobe et al. 1997, Hayakawa et al. 1997).

Waxy wheat only made poor qualities of bread and noodles (Morita et al. 2002b, Baik and Lee 2003, Park and Baik 2004b). Blends of waxy and non-waxy wheat result in high loaf volume and less staling of the breadcrumb (Lee et al. 2001, Morita et al. 2002a) and improved texture of noodles (Guo et al. 2003, Baik and Lee 2003). Blends from 10 to $20 \%$ of waxy flour to non-waxy flour were found to improve noodle and bread quality (Yamaguchi et al. 2003). On the other hand, flour yield, milling score and flour brightness of two waxy wheat varieties were less than those of the nonwaxy wheat Norin 61 (Yamaguchi et al. 2003).

Near isogenic lines for waxy protein have been investigated for quality differences. Miura et al. (2002) developed NILs carrying null waxy proteins of Chinese Spring and reported on their starch properties. The qualities of waxy wheat starch properties are also important for breeding. We have developed a near isogenic line having the null waxy proteins in a spring wheat cultivar Harunoakebono, which

Communicated by Andris Kleinhofs

Received May 19, 2004. Accepted September 21, 2004.

*Corresponding author (e-mail: takata@affrc.go.jp) has good bread making quality. Our purpose was to elucidate grain and flour properties of waxy wheat for improving bread quality, and to estimate the bread making quality of a waxy wheat with strong gluten.

\section{Plant materials}

Harunoakebono, a spring wheat cultivar with hard grain and good bread-making quality, shows a null allele at $w x-B 1$. It was crossed with MochimorikeiC-D1478 (Hatsumochi), a waxy wheat line derived from a cross between Kanto 107 ( $w x-A 1$ and $B 1$ null) and Bai Huo ( $w x-D 1$ null). Backcrossed plants with both waxy and non-waxy pollen which were checked by an iodine solution $\left(0.2 \% \mathrm{KI}, 0.04 \% \mathrm{I}_{2}, \mathrm{~W} / \mathrm{V}\right)$ successively backcrossed five times to the recurrent parent Harunoakebono. A near isogenic line (NIL) having triple null waxy proteins was selected by iodine staining in $\mathrm{B}_{5} \mathrm{~F}_{2}$ seeds and checked in $\mathrm{B}_{5} \mathrm{~F}_{3}$ by electrophoresis as described by Nakamura et al. (1993) with modifications (15\% SDS polyacrylamide gel with an acrylamide/BIS ratio 30:0.135). The waxy NIL and Harunoakebono were cultivated with three replicates at the HNARC in 2002.

\section{Grain and flour characteristics}

The grain characteristics (weight, diameter and hardness) were measured with an SKCS 4100 (Perten Co. Ltd., USA). Water was added to grain samples to $16 \%$ moisture basis and were left over night. The samples were milled with Buhler test mill MLU202 (Buhler Inc., Switzerland) at the hard-grain setting and $60 \%$ extraction flour was obtained. The ash content of grain and flour were measured by the furnace ash method. Flour protein content was measured with near-infrared spectroscopy using an Inframatic 8120 (PerCon, Germany). Polyphenol content was measured by a Prussian blue assay, for which $0.2 \mathrm{~g}$ of four was first mixed with $5 \mathrm{ml}$ of methanol and shaken for $20 \mathrm{~min}$. The solutions were then allowed to stand for one hour and were centrifuged at $2,000 \mathrm{rpm}$ for $5 \mathrm{~min}$ at $5^{\circ} \mathrm{C}$. The supernatant was 
mixed with $0.005 \mathrm{M} \mathrm{K}_{3} \mathrm{Fe}(\mathrm{CN})_{6}$ and $0.4 \mathrm{M} \mathrm{FeCl}_{3}$ in $0.1 \mathrm{~N} \mathrm{HCl}$ and incubated for one hour at $25^{\circ} \mathrm{C}$. The absorbance was measured with a spectrophotometer at $710 \mathrm{~nm}$, and the polyphenol content was calculated from a catechin calibration line. Arabinoxylan content was measured by a minor modification of the phloroglucinol method of Henry (1985). Five $\mathrm{mg}$ of flour dispensed in $1 \mathrm{ml}$ of distilled water was mixed with $5 \mathrm{ml}$ of an extract solution of $1 \mathrm{~g}$ of phloroglucinol, $5 \mathrm{ml}$ of ethanol, $10 \mathrm{ml}$ of acetic acid, $2 \mathrm{ml}$ of hydrochloric acid, and $1 \mathrm{ml}$ of $1.75 \%$ glucose, and heated in boiling water for $30 \mathrm{~min}$. The difference in absorbance at $625 \mathrm{~nm}$ and $552 \mathrm{~nm}$ was measured after cool-down. Flour color was measured on a slurry of $6 \mathrm{~g}$ of flour with $8 \mathrm{ml}$ of distilled water using a Minolta CM-3500d (Minolta Co., Ltd., Japan). The flour color were expressed as $\mathrm{L}^{*}, \mathrm{a}^{*}$ and $\mathrm{b}^{*}$, which refer to the white-to-black, red-to-green and yellow-to-blue axes, respectively. Flour particle size expressed as median of flour particle size was measured by a laser-diffraction Heros and Rodos particle-size analyzer (Japan Laser Co. Ltd., Japan).

Pasting properties of the starches were determined by a rapid visco-analyzer (RVA). Starch was purified from $30 \mathrm{~g}$ of flour by hand washing three times with distilled water and prepared after air-drying at room temperature. An amount of $2.5 \mathrm{~g}$ of starch was dispersed into $25 \mathrm{ml}$ of distilled water. The RVA was set at $50^{\circ} \mathrm{C}$ for $1 \mathrm{~min}$, then heated to $95^{\circ} \mathrm{C}$ at a rate of $12^{\circ} \mathrm{C} / \mathrm{min}$ temperature increase, and held for $2.5 \mathrm{~min}$; it was then cooled to $50^{\circ} \mathrm{C}$ at a rate of $12^{\circ} \mathrm{C} / \mathrm{min}$ temperature decrease and held for $3 \mathrm{~min}$.

Physical dough properties were determined using a farinograph (Brabender Inc., Germany) and a 2g-mixograph (National Mfg., USA). Farinograph analyses were performed with $50 \mathrm{~g}$ of flour according to AACC method 08-01. A 2g-mixograph was performed by AACC method 54-40A. Water absorption in the mixograph used the water absorption determined by farinograph, because of the high water absorption by waxy wheat.

\section{Baking test}

Waxy wheat, Harunoakebono and their blended flours were tested for bread making quality. The waxy wheat was blended with Harunoakebono at 5, 10, 20 and 40 percentages. Water content of flour from Harunoakebono and waxy wheat were determined by water absorption of 500B.U. of farinograph. The water contents of the blended flours were determined by the proportion of waxy wheat and non-waxy wheat. A baking test was performed by the no-time method (Takata et al. 2000), $200 \mathrm{~g}$ of flour, $10 \mathrm{~g}$ of sugar, $10 \mathrm{~g}$ of shortening, $4 \mathrm{~g}$ of salt, $4 \mathrm{~g}$ of yeast, and $100 \mathrm{ppm}$ of ascorbic acid were used for this test. Dough was divided into three $100 \mathrm{~g}$ of dough pieces and two $20 \mathrm{~g}$ of dough pieces. Each $100 \mathrm{~g}$ of dough was panned and proofed at $38^{\circ} \mathrm{C}$ for $70 \mathrm{~min}$; then, the dough pieces were baked at $200^{\circ} \mathrm{C}$ for $25 \mathrm{~min} . \mathrm{CO}_{2}$ production from $20 \mathrm{~g}$ of dough was checked by the fermograph II (ATTO Co., Tokyo) at $30^{\circ} \mathrm{C}$ for $300 \mathrm{~min}$. Loaf volume was measured at an hour after baking. All flour samples were duplicated the baking, then six loaves were obtained from the waxy NIL, Harunoakebono and the blended flours, respectively. Each loaf was then sealed in a plastic bag and stored at $20^{\circ} \mathrm{C}, \mathrm{RH} 70 \%$ for one, two and three days. Two loaves were used the compressing test each day. The loaves were sliced with a thickness of $2 \mathrm{~cm}$, and the center of the slice was cut into a square $(3 \mathrm{~cm} \times 3 \mathrm{~cm})$. Crumb firmness was measured six slices by compressing a crumb of $2 \mathrm{~cm}$ thickness to $1 \mathrm{~cm}$ with a Rheoner model RE33005 (Yamauchi et al. 1999).

\section{Estimation of grain and flour characteristics}

There were no significant differences in content of grain ash, grain hardness, grain weight and grain diameter between the NIL (waxy wheat) and Harunoakebono (Table 1). Their grain hardness proved the grains to be hard. Therefore, they were milled at a hard-grain setting. The milling and flour characteristics are shown in Table 2. Flour yield and milling score of the waxy NIL were significantly lower than those of Harunoakebono. Yasui et al. (1999) and Graybosch et al. (2003) reported that the flour yield of waxy wheat was lower than that of non-waxy wheat. Yasui et al. (1999) suggested that the beta-glucan and fat increase in waxy wheat influenced the flour yield. Kato et al. (1997) reported varieties having a low flour yield had a high arabinoxylan content in their flours. The arabinoxylan content of the NIL was higher than that of Harunoakebono. It was considered that the high arabinoxylan content of the waxy wheat caused the low flour yield. Kiribuchi-Otobe et al. (2002) suggested that the flour yield of waxy wheat could be improved by lowering the arabinoxylan content. However, it will be difficult to improve the flour yield of waxy wheat.

In this study, we milled the waxy wheat at a hard-grain setting based on the grain hardness. Both the NIL and Harunoakebono showed near the median flour particle size,

Table 1. Grain quality characteristics of near isogenic line (NIL) of waxy and recurrent parent Harunoakebono

\begin{tabular}{lcccc}
\hline \hline Materials & Ash $(\%)$ & Weight $(\mathrm{mg})$ & Diameter $(\mathrm{mm})$ & Hardness $(\mathrm{HI})$ \\
\hline Harunoakebono & $1.9 \pm 0.1$ & $32.3 \pm 0.8$ & $2.32 \pm 0.04$ & $73.8 \pm 0.3$ \\
& $(1.9-2.0)$ & $(31.4-32.9)$ & $(2.29-2.37)$ & $(73.5-74.0)$ \\
NIL & $2.0 \pm 0.1$ & $32.2 \pm 1.6$ & $2.34 \pm 0.08$ & $77.1 \pm 2.4$ \\
& $(1.9-2.1)$ & $(31.2-34.0)$ & $(2.29-2.43)$ & $(74.5-79.1)$ \\
\hline
\end{tabular}

The values express means \pm standard deviations.

The values in parentheses indicate ranges. 
Table 2. Flour yield and flour quality characteristics of near isogenic line (NIL) of waxy and Harunoakebono

\begin{tabular}{lccccc}
\hline \hline Materials & $\begin{array}{c}\text { Flour yield } \\
(\%)\end{array}$ & Milling Score & $\begin{array}{c}\text { Ash } \\
(\%)\end{array}$ & $\begin{array}{c}\text { Particle size } \\
(\mu \mathrm{m})\end{array}$ & $\begin{array}{c}\text { Protein } \\
(\%)\end{array}$ \\
\hline Harunoakebono & $73.2 \pm 0.6$ & $81.9 \pm 1.2$ & $0.43 \pm 0.02$ & $58.7 \pm 1.9$ & $13.2 \pm 0.4$ \\
& $(72.6-73.8)$ & $(81.2-83.3)$ & $(0.41-0.45)$ & $(56.7-60.5)$ & $(13.2-13.6)$ \\
NIL & $68.3 \pm 0.8^{* *}$ & $73.1 \pm 3.1^{* *}$ & $0.48 \pm 0.01^{*}$ & $61.6 \pm 0.5$ & $12.9 \pm 0.4$ \\
& $(67.8-69.3)$ & $(70.8-76.6)$ & $(0.48-0.49)$ & $(61.1-62.1)$ & $(12.8-13.6)$ \\
\hline \hline \multirow{2}{*}{ Materials } & Arabinoxyran & Polyphenol & & & \\
\cline { 3 - 6 } & $(\%)$ & $(\mathrm{mg} / \mathrm{g})$ & $\mathrm{L}^{*}$ & Flour color ${ }^{1)}$ & \\
\hline Harunoakebono & $1.17 \pm 0.02$ & $0.173 \pm 0.010$ & $87.4 \pm 0.2$ & $1.08 \pm 0.04$ & $15.7 \pm 0.2$ \\
& $(1.16-1.19)$ & $(0.164-0.183)$ & $(87.2-87.6)$ & $(1.04-1.12)$ & $(15.5-15.9)$ \\
NIL & $1.29 \pm 0.05^{*}$ & $0.277 \pm 0.006^{* * *}$ & $86.3 \pm 0.2^{* *}$ & $0.95 \pm 0.07 *$ & $16.4 \pm 0.3^{*}$ \\
& $(1.23-1.32)$ & $(0.273-0.284)$ & $(86.0-86.5)$ & $(0.88-1.02)$ & $(16.1-16.7)$ \\
\hline
\end{tabular}

1) $L^{*}$ : Brightness, $a^{*}$ : redness-greenness, $b^{*}$ : yellowness-blueness.

The values express means \pm standard deviations.

The values in parentheses indicate ranges.

$*, * *$ and $* * *$ indicate significant difference at $5 \%, 1 \%$ and $0.1 \%$ levels, respectively, by $t$-test.

and the distribution plot of flour particles showed the flours to be from hard grain. Bettge et al. (2000) reported that waxy starch granules were more damaged in milling than normal starch because of the greater susceptibility to mechanical damage of the waxy starch. Waxy starch is considered a new quality trait in bread wheat. Therefore it is necessary to optimize the milling for waxy wheat in practice.

Brightness of flour from the NIL was lower than that of Harunoakebono, which showed low L*. As protein content increases, the brightness of flour generally becomes lower. However, there was no significant difference in protein content between the waxy NIL and Harunoakebono. The difference of flour color between the waxy NIL and Harunoakebono was not affected by the protein content. Flour ash content of the waxy NIL was significantly higher than that of Harunoakebono; similar results were reported by Morita et al. (2002b) and Graybosch et al. (2003). The flour ash content is known to influence the brightness of flour. Polyphenol content was significantly higher for the NIL. Relationships were observed between the polyphenol content and the brightness of flour (Yoshikawa et al. 2001, Takata et al. 2002). The high ash content and high polyphenol content of the NIL were related to the brightness of flour. The $a^{*}$ and $b^{*}$ of the NIL were significantly different from Harunoakebono.
The reason for low $a^{*}$ and high $b^{*}$ in the waxy NIL was not clear.

Starch viscosity from RVA was definitely different between NIL and Harunoakebono (Table3). Starch of NIL showed higher peak viscosity and much lower peak temperature than that of Harunoakebono. Breakdown was higher, and set back was lower for NIL. Kiribuchi-Otobe et al. (1997) and Miura et al. (2002) was reported the peak viscosity of waxy starch was higher than that of non waxy starch. Graybosch et al. (2003) reported that there was no difference between waxy and non-waxy starch. Hayakawa et al. (1997) reported that the waxy starch had lower peak viscosity than the nonwaxy starch. The results suggest that the peak viscosity is affected by environment and genetic background. The peak temperature, breakdown and setback were stable properties in all tests.

The physical dough properties resulting from farinograph and mixograph are presented in Table 4. Farinograph water absorption was significantly higher for the waxy NIL as the results of Guo et al. (2003). Since the water absorption was considerably high, it was quite different from the water absorption formula of mixograph. The water absorption of mixograph was used the farinograph water absorption. The waxy starch granules were more damaged than the non-

Table 3. Results of rapid visco analyzer (RVA) of strach from near isogenic line (NIL) of waxy and Harunoakebono

\begin{tabular}{ccccc}
\hline \hline Materials & $\begin{array}{c}\text { Peak viscosity } \\
(\mathrm{RVU})\end{array}$ & $\begin{array}{c}\text { Peak temp. } \\
\left(\mathrm{C}^{\mathrm{O}}\right)\end{array}$ & $\begin{array}{c}\text { Break down } \\
(\mathrm{RVU})\end{array}$ & $\begin{array}{c}\text { Set back } \\
(\mathrm{RVU})\end{array}$ \\
\hline Harunoakebono & $156 \pm 1$ & $94.9 \pm 0.1$ & $28 \pm 1$ & $75 \pm 6$ \\
& $(155-157)$ & $(94.8-95.0)$ & $(27-30)$ & $(69-81)$ \\
NIL & $251 \pm 6^{* * *}$ & $76.4 \pm 0.6^{* * *}$ & $154 \pm 4^{* * *}$ & $16 \pm 1^{* * *}$ \\
& $(246-258)$ & $(75.8-76.9)$ & $(151-158)$ & $(15-17)$ \\
\hline
\end{tabular}

The values express means \pm standard deviations.

The values in parentheses indicate ranges.

*** indicates significant difference at $0.1 \%$ level by $t$-test. 
Table 4. Results of farinograph and mixograph of near isogenic line (NIL) of waxy and Harunoakebono

\begin{tabular}{|c|c|c|c|c|}
\hline \multirow[b]{2}{*}{ Materials } & \multicolumn{4}{|c|}{ Farinograph } \\
\hline & $\begin{array}{c}\text { Water absorption } \\
(\%)\end{array}$ & $\begin{array}{l}\text { Development time } \\
\text { (min) }\end{array}$ & $\begin{array}{l}\text { Stability } \\
(\min )\end{array}$ & $\begin{array}{l}\text { Weakness } \\
\text { (BU) }\end{array}$ \\
\hline Harunoakebono & $\begin{array}{l}63.0 \pm 2.3 \\
(60.3-64.5)\end{array}$ & $\begin{array}{l}6.1 \pm 2.1 \\
(3.7-7.7)\end{array}$ & $\begin{array}{c}18.0 \pm 7.4 \\
(13.2-26.5)\end{array}$ & $\begin{array}{l}33 \pm 20 \\
(20-45)\end{array}$ \\
\hline \multirow[t]{2}{*}{ NIL } & $\begin{array}{r}72.1 \pm 1.1 * * \\
(70.9-73.0)\end{array}$ & $\begin{array}{l}9.9 \pm 1.6 \\
(8.8-11.7)\end{array}$ & $\begin{array}{c}8.1 \pm 2.3 \\
(6.5-10.8)\end{array}$ & $\begin{array}{c}72 \pm 10^{*} \\
(60-80)\end{array}$ \\
\hline & \multicolumn{4}{|c|}{ Mixograph } \\
\hline Materials & $\begin{array}{l}\text { Mixing peak time } \\
\text { (min) }\end{array}$ & $\begin{array}{l}\text { Peak height } \\
(\%)\end{array}$ & $\begin{array}{c}\text { Peak band width } \\
(\%)\end{array}$ & Envelope area \\
\hline Harunoakebono & $\begin{array}{c}4.1 \pm 0.3 \\
(3.7-4.3)\end{array}$ & $\begin{array}{c}39.4 \pm 2.2 \\
(37.0-41.2)\end{array}$ & $\begin{array}{l}27.3 \pm 1.5 \\
(25.6-28.4)\end{array}$ & $\begin{array}{c}48.8 \pm 4.0 \\
(44.3-51.9)\end{array}$ \\
\hline NIL & $\begin{array}{c}4.2 \pm 0.1 \\
(4.1-7.3)\end{array}$ & $\begin{array}{l}38.1 \pm 5.4 \\
(32.4-43.1)\end{array}$ & $\begin{array}{c}22.5 \pm 2.3^{*} \\
(21.1-25.2)\end{array}$ & $\begin{array}{c}33.9 \pm 4.4^{*} \\
(31.1-39.0)\end{array}$ \\
\hline
\end{tabular}

The values express means \pm standard deviations.

The values in parentheses indicate ranges.

$*$ and $* *$ indicate significant difference at $5 \%$ and $1 \%$ levels, respectively, by $t$-test.

waxy starch granules (Bettge et al. 2000). Guo et al. (2003) reported that the damaged starch of waxy wheat content was higher than that of non-waxy wheat. However, Park and Baik (2004a) reported that the damaged starch content did not differ between waxy wheat and non-waxy wheat, and suggested differences in milling condition and the assay for damaged starch. The damaged starch granules have a high water absorption. The high water absorption could be ascribed to the damaged starch granules of waxy wheat. Park and Baik (2004a) suggested that high flour water absorption of waxy wheat could be due to other starch properties than the damaged starch. In addition, the arabinoxylan content also influenced water absorption (Kim and D'Appolonia 1977, Michniewicz et al. 1991). It also influenced the water absorption of the waxy wheat flour. There were no significant differences in development time and farinograph stability in agreement with Morita et al. (2002b), except for the greater weakness of the waxy wheat. There were no significant differences in mixograph mixing time and peak height. The NIL showed strong dough properties like that of Harunoakebono. It was suggested that introducing strong gluten improved the physical properties of waxy wheat. Peak bandwidth and envelope area of the mixograph were significantly smaller for the NIL. The water absorption affected parameters, such as the peak band width, envelope area of mixograph and the weakness of the farinograph. This should be kept in mind for the uses of waxy wheat in food processing.

\section{Baking test of blended flour}

The results of baking tests are shown in Figures 1 and 2. Mixing peak time of the NIL (100\% waxy wheat) was 30 seconds shorter than that of Harunoakebono. The bread dough of the NIL was slightly stickier than that of

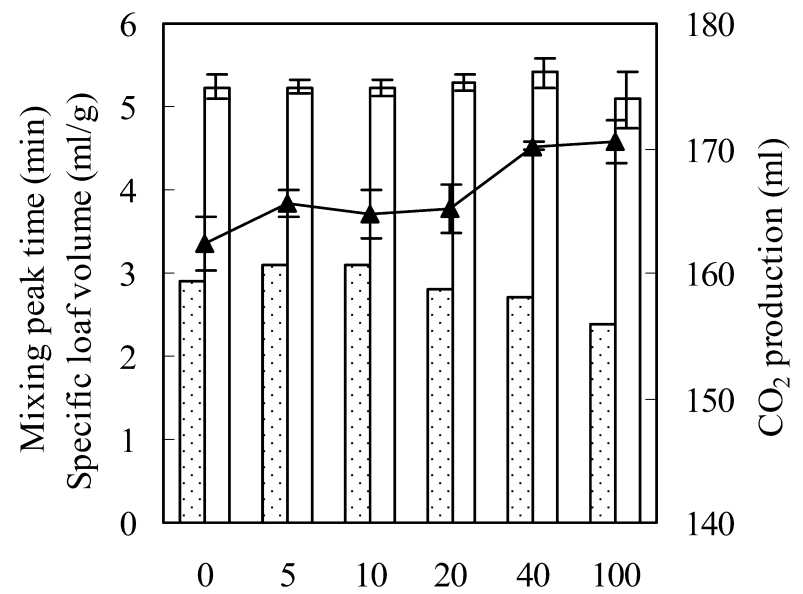

Percentage of waxy wheat flour

Fig. 1. Changes of mixing peak time, specific loaf volume and $\mathrm{CO}_{2}$ production of dough of waxy wheat blends to Harunoakebono. $\because \because$ mixing peak time, $\square$ specific loaf volume, $\mathbf{\Delta} \mathrm{CO}_{2}$ production. Bars indicate the standard deviation.

Harunoakebono. This, however, did not affect the handling of the dough. The mixing time generally lengthens as the amount of water increases in the same variety. This baking test of the waxy wheat blend indicated that the mixing peak time was shortened by more than $20 \%$ of the waxy wheat blend. The reason seemed to be the interaction between waxy wheat flour and ingredients of the baking formula, because the mixograph mixing peak time of the NIL flour was not different from that for Harunoakebono. $\mathrm{CO}_{2}$ production from the doughs of waxy wheat blends was higher than that for Harunoakebono doughs. Lee et al. (2001) reported higher gas formation for doughs made from blend of reconstituted waxy wheat. The $\mathrm{CO}_{2}$ production from the $40 \%$ waxy wheat 


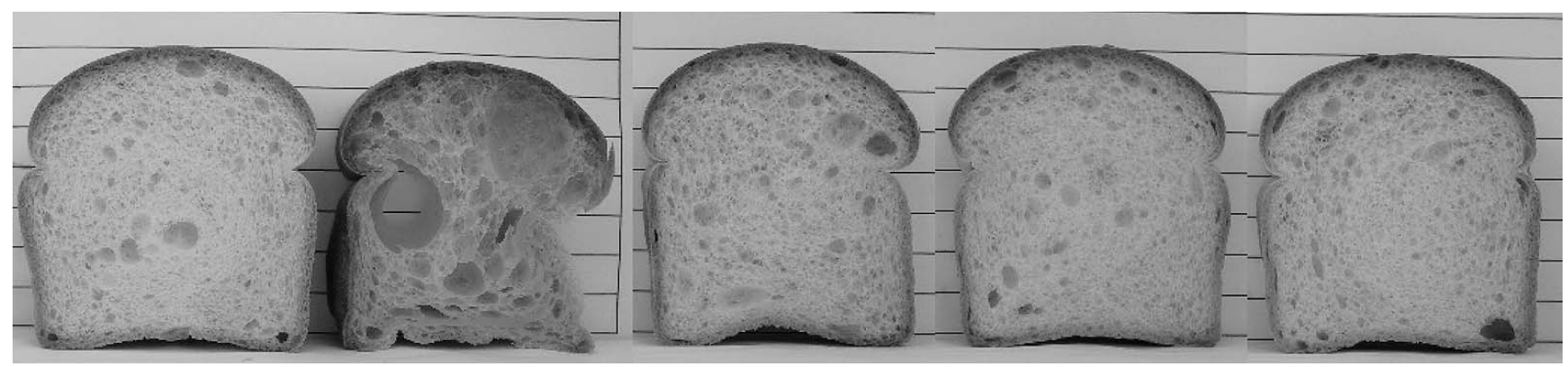

Percentage of waxy wheat blends

$0 \%$

\section{(Harunoakebono)}

Fig. 2. Slices of bread of waxy wheat blends to Harunoakebono.

blend and the waxy NIL was higher than that of the others. High proportion of amylopectin in waxy flour blends provided fermentable sugars increased gas formation of dough (Lee et al. 2001), and besides higher damaged starch granules for waxy wheat were assumed to be the reason for high $\mathrm{CO}_{2}$ production.

The specific loaf volume of the NIL was less than that of Harunoakebono; however, the $\mathrm{CO}_{2}$ production of the former was higher than that of the latter. The loaf of the NIL shrank during storage because of the large gas cells (Fig. 2). Specific loaf volume was not different among waxy wheat blends and Harunoakebono, except for the $40 \%$ waxy wheat blend, whose specific loaf volume was slightly higher than that of the others. Our result that the loaf volumes of waxy wheat blend were equal to those of non-waxy wheat differs from the results of Lee et al. (2001) and Morita et al. (2002a). However, the wheat materials and baking method differed from each other. Both $\mathrm{CO}_{2}$ production and dough strength support the baking results in this experiment. The loaf and crumb color of the NIL were much darker than those of Harunoakebono and the waxy wheat blends. The loaf and crumb color of the $40 \%$ waxy wheat blend were darker than those of the other waxy wheat blends.

Crumb firmness of waxy wheat blends was less than that of Harunoakebono after one day of storage (Fig. 3). However, except for the $40 \%$ waxy wheat blend, the crumb firmness of waxy wheat blends was equal to that of Harunoakebono at two days of storage. The crumb firmness of the $40 \%$ waxy wheat blend at two days of storage was nearly equal to that after a day of storage. The crumb firmness of the $40 \%$ waxy wheat blend rose quickly at three days of storage; however, it was less than the others. A 20\% waxy wheat blend gave a soft crumb after storage, as in other reports (Lee et al. 2001, Morita et al. 2002a). However, the blends with less than $20 \%$ of waxy wheat had only a small effect on crumb firmness at two days of storage. The null $w x-B 1$ of Harunoakebono may be related to the staleness of crumb, because of the null $w x-B 1$ influence on the viscosity of starch and elasticity of noodles. It is necessary to research

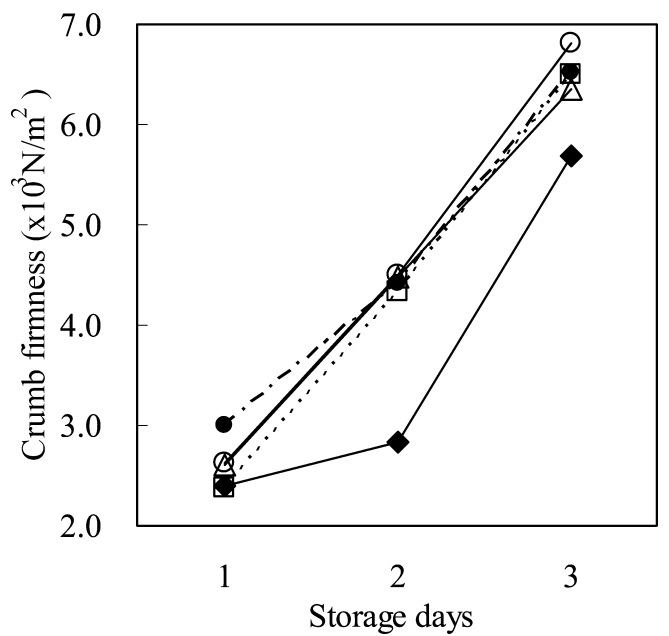

Fig. 3. Crumb firmness of bread of waxy wheat blends to Harunoakebono. Percentage of waxy flour at $0 \%(\bigcirc), 5 \%(\bigcirc), 10 \%$ $(\triangle), 20 \%(\square)$ and $40 \%($

the bread staleness of waxy wheat blend in the round.

The waxy NIL was lower flour yield and milling score compared with non-waxy wheat. Flour ash and polyphenol content of the NIL was higher than those of non-waxy wheat. Farinograph water absorption was considerable higher for the NIL. Physical dough properties, such as farinograph development time and mixograph mixing time, of the NIL were comparable with non-waxy wheat. The peak band width, envelope area of mixograph and farinograph weakness indicated weaker gluten properties for the NIL because of high flour water absorption. Use of the near isogenic line made it clear that it will be difficult to improve some quality characteristics in waxy wheat. Blends of waxy flour to nonwaxy flour were influence to end products because of low amylase content, low brightness of flour and high flour water absorption. While 5 to $20 \%$ of waxy flour blends were small effects on crumb firmness, the bread of the $40 \%$ waxy flour blend was softer crumb than that of non-waxy flour for three days of storage. Waxy wheat with strong gluten, as in 
this study, also will contribute favorably for the using waxy wheat in food processing.

\section{Acknowledgements}

This study was supported in part by a grant for a Research and Development Program of New Bio-industry Initiatives from National Agriculture and Bio-oriented Research Organization in Japan. We thank Dr. Miura at Obihiro University for the advice of the electrophoresis.

\section{Literature Cited}

Baik,B.-K. and M.-R.Lee (2003) Effects of starch amylase content of wheat on textural properties of white salted noodles. Cereal Chem. 80: 304-309.

Bettge, A.D., M.J.Giroux and C.F.Morris (2000) Susceptibility of waxy starch granules to mechanical damage. Cereal Chem. 77 : 750-753.

Graybosch,R.A., E.Souza, W.Berzonsky, S.Baenziger and O.Chung (2003) Functional properties of waxy wheat flours: genotypic and environmental effects. J. Cereal Sci. 38: 69-76.

Guo, G., D.S. Jackson, R.A. Graybosch and A.M.Parkhurst (2003) Asian salted noodle quality: Impact of amylose content adjustments using waxy wheat flour. Cereal Chem. 80: 437-445.

Hayakawa,K., K.Tanaka, T.Nakamura, S.Endo and T.Hoshino (1997) Quality characteristics of waxy hexaploid wheat (Triticum aestivum L.): Properties starch gelatinisation and retrogradation. Cereal Chem. 74: 576-580.

Henry, R.J. (1985) A comparison of the non-starch carbohydrates in cereal grains. J. Sci. Food Agric. 36: 1243-1253.

Kato,T., S.Kaneko, T.Ushiyama and K.Komae (1997) Cell wall polysaccharides of wheat endosperm having different milling performance. Breed. Sci. 47 (Suppl. 1): 304 (in Japanese).

Kim, S.K. and B.L.D'Appolonia (1977) Bread staling studies. III. Effect of pentosans on dough, bread, and bread staling rate. Cereal Chem. 54: 225-229.

Kiribuchi-Otobe, C., T.Nagamine, T. Yanagisawa, M.Ohnishi and I. Yamaguchi (1997) Production of hexaploid wheats with waxy endosperm character. Cereal Chem. 74: 72-74.

Kiribuchi-Otobe,C., T.Kato, T.Yanagisawa, M.Fujita and K.Komae (2002) Improvement of flour yield of waxy by lowering the arabinoxylan content. Breed. Res. 4 (Suppl.1): 200 (in Japanese).

Lee,M.-R., B.G.Swanson and B.-K.Baik (2001) Influence of amylose content on properties of wheat starch and breadmaking quality of starch and gluten blends. Cereal Chem. 78: 701-706.

Michniewicz,J., C.G.Biliaderis and W.Bushuk (1991) Effect of added pentosans on some physical and technological characteristics of dough and gluten. Cereal Chem. 68: 252-258.

Miura,H., M.H.A.Wickramasinghe, R.M. Subashinghe, E. Araki and
K. Komae (2002) Development of near-isogenic lines of wheat carrying different null $w x$ alleles and their starch properties. Euphtica 123: 353-359.

Morita, N., T.Maeda, M.Miyazaki, M. Yamamori, H. Miura and I.Ohtsuka (2002a) Effect of substitution of waxy-wheat flour for common flour on dough and baking properties. Food Sci. Technol. Res. 8: 119-124.

Morita, N., T.Maeda, M.Miyazaki, M. Yamamori, H.Miura and I. Ohtsuka (2002b) Dough and baking properties of highamylose and waxy wheat flours. Cereal Chem. 79: 491-495.

Nakamura, T., M.Yamamori, H.Hirano and S.Hidaka (1993) Identification of three waxy proteins in wheat (Triticum aestivum L.). Bio. Chem. Genet. 31: 75-86.

Nakamura,T., M.Yamamori, H.Hirano, S.Hidaka and T.Nagamine (1995) Production of waxy (amylose-free) wheats. Mol. Gen. Genet. 248: 253-259.

Park, S.C. and B.-K.Baik (2004a) Cooking time of white salt noodles and its relationship with protein and amylase contents of wheat. Cereal Chem. 81: 165-171.

Park, S.C. and B.-K. Baik (2004b) Significance of amylase content of wheat starch on processing and textural properties of instant noodles. Cereal Chem. 81: 521-526.

Takata,K., H.Yamauchi, Z.Nishio and T.Kuwabara (2000) Effect of high molecular weight glutenin subunits on bread-making quality using near-isogenic lines. Breed. Sci. 50: 303-308.

Takata,T., Y.Fujita, Z.Nishio, T.Kuwabara and H.Miura (2002) Relationships between flour components and flour colour with alkaline water. 52nd Australian Cereal Chemistry Conference Handbook: 76.

Yamaguchi,I., C.Kiribuchi-Otobe, T.Yanagisawa, T.Nagamine, T. Ushiyama and H.Yoshida (2003) Breeding of 2 waxy wheat cultivars "Akebono-mochi" and "Ibuki-mochi", and their main features. Bull. Natl. Inst. Crop Sci. 3: 21-33 (in Japanese).

Yamauchi, H., Y. Ichinose, K. Takata, N. Iriki, T. Shiina and T. Kobayashi (1999) A kinetic study on stealing of white bread made by frozen dough method. Nippon Shokuhin Kagaku Kougaku Kaishi 46: 212-219 (in Japanese).

Yasui,T., J.Matsuki, T.Sasaki and M.Yamamori (1996) Amylose and lipid contents, amylopectin structure, and gelatinisation properties of waxy wheat (Triticum aestivum) starch. J. Cereal Sci. 24: 131-137.

Yasui,T., T.Sasaki, J.Matsuki and M.Yamamori (1997) Waxy endosperm mutants of bread wheat (Triticum aestivum L.) and their starch properties. Breed. Sci. 47: 161-163.

Yasui,T., T.Sasaki and J.Matsuki (1999) Milling and flour pasting properties of waxy endosperm mutant lines of bread wheat (Triticum aestivum L). J. Sci. Food Agric. 79: 687-692.

Yoshikawa,R., M.Ito and K.Nakamura (2001) Relationships among total polyphenol content, milling properties and flour qualities in wheat cultivars and lines. Breed. Res. 3 (Suppl. 1): 140 (in Japanese). 